\title{
Exercise-induced ventricular arrhythmias and vagal dysfunction in Chagas disease patients with no apparent cardiac involvement
}

\author{
Henrique Silveira Costa ${ }^{[1]}$, Maria Carmo Pereira Nunes ${ }^{[1]}$, Aline Cristina de Souza ${ }^{[1]}$, \\ Marcia Maria Oliveira Lima ${ }^{[2]}$, Renata Bicalho Carneiro ${ }^{[1],}$ \\ Giovane Rodrigo de Sousa ${ }^{[1]}$ and Manoel Otávio da Costa Rocha ${ }^{[1]}$
}

[1]. Curso de Pós-Graduação em Ciências da Saúde: Infectologia e Medicina Tropical, Faculdade de Medicina, Universidade Federal de Minas Gerais, Belo Horizonte, Minas Gerais, Brasil. [2]. Departamento de Fisioterapia, Faculdade de Ciências da Saúde, Universidade Federal dos Vales do Jequitinhonha e Mucuri, Diamantina, Minas Gerais, Brasil.

\begin{abstract}
Introduction: Exercise-induced ventricular arrhythmia (EIVA) and autonomic imbalance are considered as early markers of heart disease in Chagas disease (ChD) patients. The objective of the present study was to verify the differences in the occurrence of EIVA and autonomic maneuver indexes between healthy individuals and $\mathrm{ChD}$ patients with no apparent cardiac involvement. Methods: A total of $75 \mathrm{ChD}$ patients with no apparent cardiac involvement, aged 44.7 (8.5) years, and 38 healthy individuals, aged 44.0 (9.2) years, were evaluated using echocardiography, symptom-limited treadmill exercise testing and autonomic function tests. Results: The occurrence of EIVA was higher in the chagasic group (48\%) than in the control group (23.7\%) during both the effort and the recovery phases. Frequent ventricular contractions occurred only in the patient group. Additionally, the respiratory sinus arrhythmia index was significantly lower in the chagasic individuals compared with the control group. Conclusions: $\mathrm{ChD}$ patients with no apparent cardiac involvement had a higher frequency of EIVA as well as more vagal dysfunction by respiratory sinus arrhythmia. These results suggest that even when asymptomatic, $\mathrm{ChD}$ patients possess important arrhythmogenic substrates and subclinical disease.
\end{abstract}

Keywords: Chagas disease. Exercise-induced ventricular arrhythmias. Autonomic function. Treadmill exercise testing.

\section{INTRODUCTION}

Chagas disease (ChD) is classified as a neglected tropical disease $^{(1)}$ and continues to be an important cause of heart failure in many countries in Latin America ${ }^{(2)}$. Beyond the endemic areas, $\mathrm{ChD}$ also represents a worldwide public health problem due to migration of infected people to developed countries, and mainly North America and Europe ${ }^{(3)}$.

In the early stages, $\mathrm{ChD}$ patients have no symptoms or electrocardiographic and radiologic abnormalities ${ }^{(4)}$. The classification with no apparent cardiac involvement has been used for asymptomatic, serologically Trypanosoma cruzi-positive patients with a normal electrocardiogram (ECG) and chest X-ray after a full or partial radiological study of the digestive tract. Because radiological studies of the digestive system of these patients have not been performed, these individuals cannot be classified when they have the indeterminate form of the disease ${ }^{(5)}$.

Corresponding author: Dr. Henrique Silveira Costa. Rua dos Guajajaras 1172/407, Centro, 30180-100 Belo Horizonte, Minas Gerais, Brasil.

Phone: 5531 3275-4205

e-mail: henriquesilveira@yahoo.com.br

Received 3 December 2014

Accepted 1 April 2015
In any case, the medical literature has indicated an excellent 10year prognosis for $\mathrm{ChD}$ patients without heart involvement ${ }^{(6)}$, although progressive myocardial damage may occur during the early stages ${ }^{(2)(7)}$. Furthermore, sudden death, mainly resulting from complications of advanced cardiac involvement, may be the first manifestation of this disease ${ }^{(8)}$, although rare structural cardiac abnormalities, ventricular arrhythmias and autonomic disturbances may also play an important role ${ }^{(9)}$.

Exercise testing is frequently used as a noninvasive assessment of myocardial ischemia that, along with patient history and physical examination, helps to characterize cardiovascular risk ${ }^{(10)}$. In addition, exercise testing can be used to identify cardiac arrhythmias, and particularly those triggered by exercise ${ }^{(11)}$. Premature ventricular contractions (PVCs) are the most frequent arrhythmias observed during exercise ${ }^{(12)}$ and may increase the risk of death through multiple mechanisms ${ }^{(13)}$, mainly because they may be markers of ischemic processes ${ }^{(14)}$ or arrhythmogenic substrates ${ }^{(15)}$. In the setting of $\mathrm{ChD}$, noninvasive clinical methods, such as evaluation of the presence of exercise-induced ventricular arrhythmia (EIVA), may be useful for identifying arrhythmogenic substrates, especially for the early detection of subclinical cardiopathy. Therefore, the aim of the present study was to verify the differences in the occurrence of EIVA and autonomic maneuver indexes between 
healthy individuals and $\mathrm{ChD}$ patients with no apparent cardiac involvement and to determine the factors associated with EIVA in $\mathrm{ChD}$ patients.

\section{METHODS}

\section{Study design}

This cross-sectional study was conducted at the Chagas Disease Outpatient Clinic and the Cardiology Service of the Hospital of the Federal University of Minas Gerais, Brazil, a tertiary $\mathrm{ChD}$ referral center.

The sample was stratified into two groups according to serology: a chagasic group and a control group. The criteria for inclusion in the chagasic group were the presence of two or more positive serological tests for $T$. cruzi, the absence of significant clinical symptoms suggestive of functional impairment due to $\mathrm{ChD}$, a chest X-ray with a normal cardiac silhouette and conventional ECG within the normal limits. The control group included healthy individuals with similar age and gender distributions as the chagasic group. The criteria for exclusion for both groups included the presence of any condition that affected the individual's ability to perform exercise testing and autonomic maneuvers.

A convenience sample was selected from the Chagas Disease Outpatient Clinic and the community. The selected individuals underwent clinical evaluation, echocardiography, and treadmill exercise and autonomic function tests.

\section{Echocardiographic evaluation}

A standard transthoracic two-dimensional (2D) echocardiogram was performed according to the recommendations of the American Society of Echocardiography ${ }^{(16)}$ using a commercially available echocardiograph (GE Vivid 7, Horten, Norway). Diastolic function was assessed as previously described ${ }^{(17)}$. The left ventricular ejection fraction (LVEF) was determined using Simpson's rule.

\section{Treadmill exercise test}

All subjects performed a symptom-limited exercise test on a treadmill (Digistress Pulsar, Micromed, Brasilia, Brazil) using the standard Bruce protocol ${ }^{(12)}$. Twelve-lead ECG was continuously monitored, with data recorded every minute. The heart rate (HR) was determined from the ECG recording. Oxygen uptake $\left(\mathrm{VO}_{2}\right)$ was estimated using a specific formula $\left(\mathrm{VO}_{2} \max (\mathrm{mL} / \mathrm{kg} / \mathrm{min})=2.33(\right.$ time in $\left.\min )+9.48\right)$ to evaluate functional capacity. Chronotropic incompetence (CI) was defined as the failure to attain $80 \%$ of the HR reserve $(\text { HR reserve }=\text { age-predicted maximal HR }- \text { resting HR })^{(18)}$.

At the recovery phase, after achieving the maximal workload, all patients spent $1 \mathrm{~min}$ in a cool-down period at a speed of $2.4 \mathrm{~km}$ per hour and a grade of $2.5 \%{ }^{(19)}$. After $1 \mathrm{~min}$, all patients completed the recovery phase in the supine position.

For the analysis of EIVA, the prevalence and the total number of PVCs during the exercise and recovery phases were considered. Frequent ventricular ectopy was defined as the presence of 7 or more ventricular premature beats per minute during any stage of the exercise test or at recovery ${ }^{(20)}$.

\section{Autonomic function tests}

Autonomic function was assessed based on Valsalva maneuvers and respiratory sinus arrhythmia. The Valsalva maneuver was performed according to Oliveira et al. ${ }^{(21)}$. In brief, in the sitting position, the patient performed a valid maneuver by blowing, with the glottis closed, into a mouthpiece connected to an aneroid manometer by tubing in order to maintain an intraoral pressure of $40 \mathrm{mmHg}$ for $15 \mathrm{~s}$ after a habitual inspiration. The maneuver was considered effective when facial plethora, neck vein distension and abdominal muscle contraction were observed.

The respiratory sinus arrhythmia test was performed with the patient in a sitting position while connected to a HewlettPackard electrocardiograph (1504 model) and wearing a nasal clip to avoid nasal respiratory loss ${ }^{(22)}$. The ratio between the longest expiratory RR interval and the shortest inspiratory RR interval (E:I ratio) was calculated for each respiratory cycle, as was the mean value for 6 cycles. The mean cardiac interval and the mean HR immediately before initiating the maneuver were obtained for the $10 \mathrm{RR}$ intervals immediately preceding the beginning of the maneuver. All calculations were based on the original maximum and minimum cardiac intervals.

\section{Statistical analysis}

The sample size used was implemented to detect the prevalence of EIVA in ChD patients based on a previous study ${ }^{(23)}$. Considering an alpha error of 0.05 , a statistical power of $95 \%$ was obtained for the sample of 78 chagasic patients.

The data were analyzed using Statistical Package for the Social Sciences (SPSS) version 17.0 (SPSS Inc., Chicago, IL, USA). The normal distribution of the data was verified using the Kolmogorov-Smirnov test. A descriptive analysis yielded the mean and $95 \%$ confidence interval (CI). Categorical variables are presented as an absolute number (percentage). A parametric unpaired t-test, Pearson's correlation test, the nonparametric Mann-Whitney test and the Spearman rank correlation test were performed for data analysis, with the significance level set at 0.05 .

\section{Ethical considerations}

This study was approved by the Ethics Committee of the Federal University of Minas Gerais, and all patients provided written informed consent before participating in this study.

\section{RESULTS}

\section{Characteristics of the sample}

Clinical and demographic characteristics, echocardiographic parameters, functional capacity and chronotropic incompetence were similar between the two groups (Table 1).

In the analysis of myocardial contractility using 2D echocardiography, segmental changes in contractility were detected in five patients. Apical akinesia (apical lesion) was found in two subjects, and hypokinesia of the basal segment of the inferior wall was identified in three patients, one of whom also showed deficits in contractility in the inferolateral wall. However, the overall contractility was preserved in all patients, with 
TABLE 1 - Characteristics of the patients.

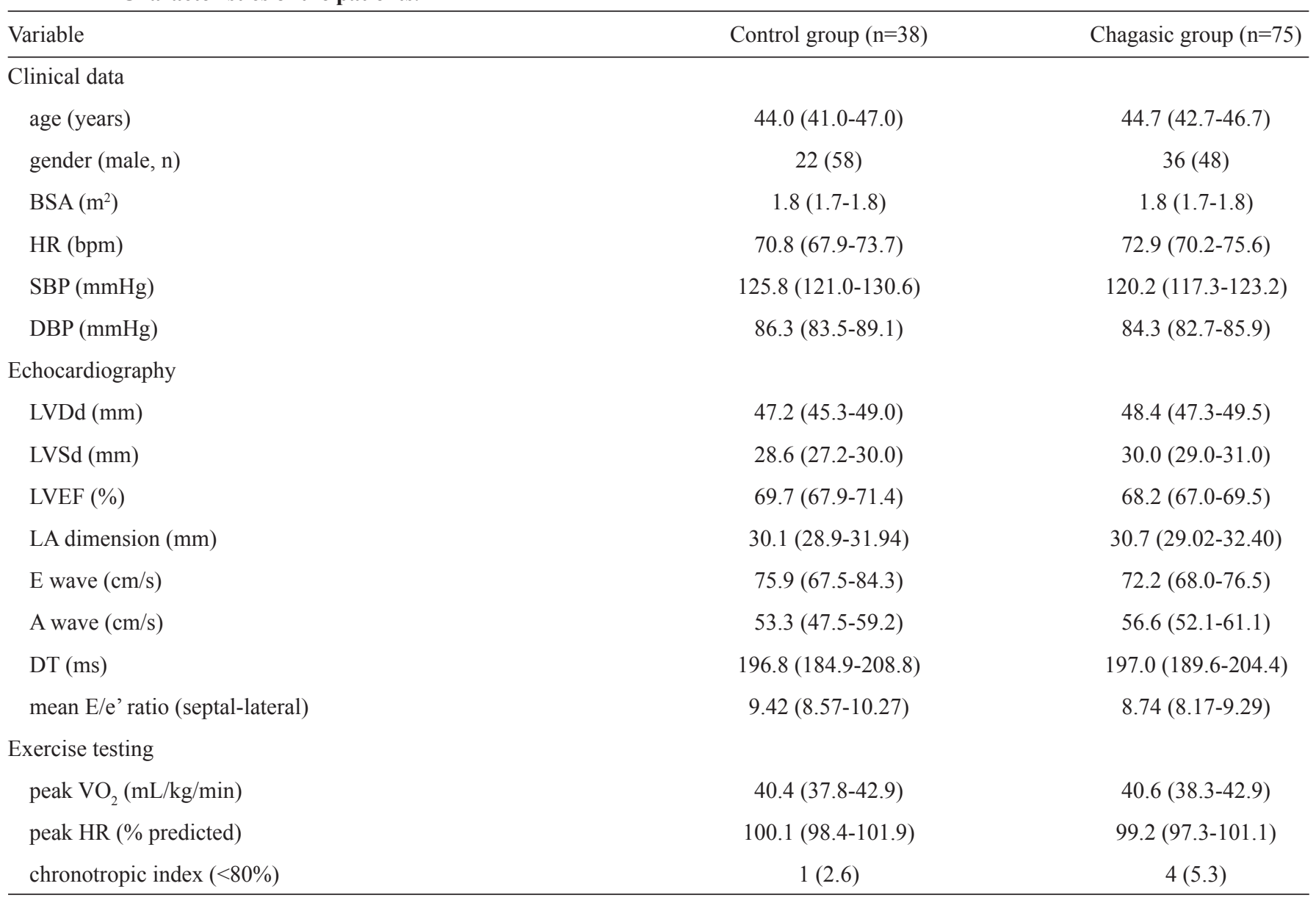

The data are presented as the mean and $95 \%$ confidence interval $(95 \% \mathrm{CI})$ or number (percentage). BSA: body surface area; HR: heart rate; bpm: beats per minute; SBP: systolic blood pressure; DBP: diastolic blood pressure, LVDd: left ventricular end-diastolic diameter; LVSd: left ventricular end-systolic diameter; LVEF: left ventricular ejection fraction; LA: left atrium; E: early diastolic transmitral flow velocity; A: late transmitral flow velocity; DT: deceleration time; E/e': ratio of the early diastolic transmitral flow velocity to the early diastolic mitral annular velocity; peak $\mathrm{VO}_{2:}$ peak oxygen uptake; peak HR (\% predicted): percentage of the maximum heart rate achieved.

normal systolic function. Table 1 shows that there was no correlation between segmental changes in contractility and the number of PVCs during exercise testing $(\mathrm{r}=0.060$; $\mathrm{p}$-value $=0.539)$.

\section{Exercise-induced ventricular arrhythmias}

The occurrence of PVCs was higher in the chagasic group: $36(48 \%)$ patients, than in the control group: nine (23.7\%) individuals, during both the effort and the recovery phases (p-value $=0.010$ for both). The total numbers of PVCs observed during treadmill exercise testing and at the recovery phase are shown in Figures $\mathbf{1}$ and 2. Frequent PVCs were observed only in the chagasic group, both during exercise testing: seven $(9.3 \%)$ patients, and at the recovery phase: three (4\%) patients. In contrast, there was no difference in the presence of ventricular tachycardia (VT) between the groups ( $\mathrm{p}$-value $=0.587$ ).

\section{Assessment of autonomic function}

In the assessment of autonomic function, there was no difference in the Valsalva ratio between the groups ( $p$-value $=0.855$ ). Moreover, no correlation was found between the Valsalva ratio and the number of PVCs during exercise or at the recovery phase $(\mathrm{r}=0.199$; $\mathrm{p}$-value $=0.102$ and $\mathrm{r}=0.085$; $\mathrm{p}$-value $=0.487$, respectively).

For respiratory sinus arrhythmia, the average ratio between the largest inspiratory and the smallest expiratory cardiac intervals was lower in $\mathrm{ChD}$ patients with no apparent cardiac involvement compared with the control group ( $p$-value $<0.001$ ). No correlation was found between the respiratory sinus arrhythmia index and the number of PVCs during exercise or at the recovery phase $(\mathrm{r}=-0.107$; $\mathrm{p}$-value $=0.381$ and $\mathrm{r}=-0.085$; $\mathrm{p}$-value $=0.400$, respectively).

\section{DISCUSSION}

The aim of the present study was to verify both the occurrence of EIVA and autonomic function indexes in $\mathrm{ChD}$ patients with no apparent cardiac involvement. The main findings of this study were: 1) a higher number of PVCs during the effort and the recovery phases of maximal exercise testing 


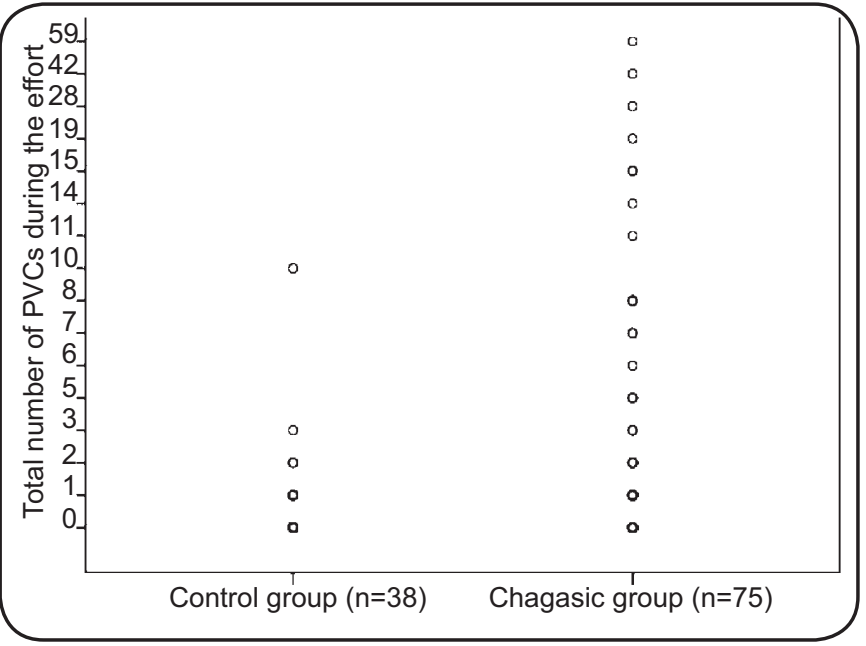

FIGURE 1 - Premature ventricular contractions during exercise testing in the control and chagasic patient groups. PVCs: premature ventricular contractions.

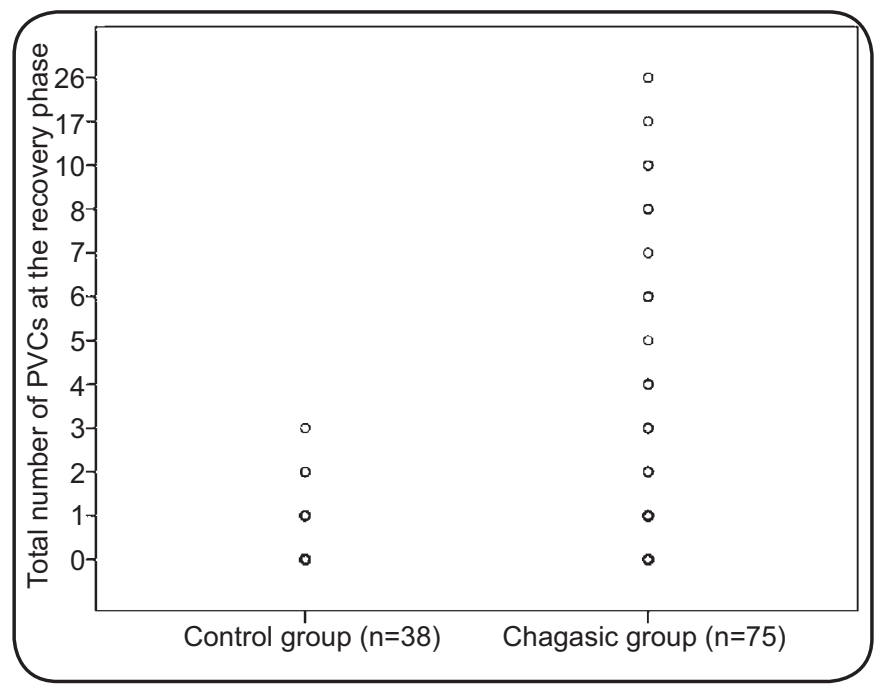

FIGURE 2 - Premature ventricular contractions at the recovery phase of exercise testing in the control and chagasic patient groups. PVCs: premature ventricular contractions.

in $\mathrm{ChD}$ patients compared with healthy individuals and frequent ventricular arrhythmias observed only in $\mathrm{ChD}$ patients and 2) lower autonomic function, as assessed based on the respiratory sinus arrhythmia index, in patients compared with healthy individuals. These findings support the concept that electrical abnormalities of the heart and autonomic imbalance may precede clinical manifestations in $\mathrm{ChD}$ patients ${ }^{(3)}{ }^{(24)}$. We also suggest that the higher occurrence of EIVA and vagal dysfunction may indicate the presence of subclinical cardiopathy in patients who are considered to be asymptomatic and to have a good prognosis.

\section{Exercise-induced ventricular arrhythmias in Chagas disease patients}

Exercise testing is an important noninvasive prognostic tool that is easily performed, without expensive resources, and the results provide a wealth of information on the state of the autonomic nervous system ${ }^{(15)}$. Moreover, a focused review ${ }^{(11)}$ showed that the majority of studies suggest that EIVA is associated with increased cardiovascular morbidity or mortality, and the occurrence of EIVA during the recovery phase of exercise testing has proven to be an even stronger predictor. However, information concerning the prevalence and prognostic implications of EIVA in ChD patients is limited ${ }^{(24)}$.

In a study ${ }^{(25)}$ of 5,754 apparently healthy male subjects, aged 63.6 (10.2) years and without atrial fibrillation and digoxin treatment, the presence of EIVA was significantly higher in individuals with cardiovascular death than in survivors (p-value $<0.001)$ after follow-up, suggesting that EIVA is an independent predictor of cardiovascular death (HR 1.6; 95\% CI: 1.1-2.1; $p$-value $=0.002$ ). Furthermore, previous longitudinal studies $^{(20)(26)}$ have demonstrated the prognostic value of frequent PVCs during exercise. Prakash et al. ${ }^{(26)}$ specifically found significant differences in the percentage of patients with frequent PVCs or ventricular tachycardia between survivors and non-survivors ( $p$-value $<0.001)$. Similarly, Frolkis et al. ${ }^{(20)}$ reported that frequent PVCs during exercise predicted a higher likelihood of death (five-year death rate, $9 \%$ vs $5 \%$ for patients without frequent PVCs during exercise; HR 1.8; 95\% CI: $1.5-2.1 ; \mathrm{p}$-value $<0.001$ ).

De Paola et al. ${ }^{(27)}$ attempted to verify the prevalence and prognostic value of EIVA in $69 \mathrm{ChD}$ patients, aged 46 (12) years, with chagasic cardiomyopathy. Ten (14\%) patients had isolated PVCs, but VT was the only variable that significantly influenced the occurrence of sudden cardiac death after a follow-up of 24 (15) years. Another study, which examined a prospective cohort ${ }^{(24)}$ of 130 Chagas heart disease patients, aged 50.7 (10.3) years, also verified the prognostic value of EIVA during a follow-up of 9.9 years (132 days to 17 years). The prevalence of EIVA was $43.1 \%$ (95\% CI: $34.5-51.7)$, and in patients with cardiomegaly, the hazard of dying was four times greater in the presence of EIVA ( $p$-value $=0.05$ ). However, in the absence of cardiomegaly or low LVEF, the authors suggested that other methods should be considered. The present study encompassed patients with no apparent cardiac involvement, and the differences in the clinical presentation of the patients did not permit additional comparisons.

In the current study, the occurrence of complex ventricular arrhythmias, such as VT, was low and not significantly different between the chagasic and the control groups. However, the patients will be followed up, and future studies will help to provide an understanding of the relationship between the presence of EIVA and the occurrence of cardiac death. In the present study, we showed a higher prevalence of EIVA in $\mathrm{ChD}$ patients compared with healthy individuals, suggesting that 
these patients, even when asymptomatic, possess important arrhythmogenic substrates and subclinical cardiopathy.

At the recovery phase of exercise testing, attenuated vagal reactivation might be associated with ventricular ectopy that is not suppressed ${ }^{(20)}$. Recently, it was demonstrated that noninvasive parameters are useful for detecting autonomic abnormalities in mild forms of $\mathrm{ChD}$ at the recovery phase of exercise testing ${ }^{(28)}$. The present study highlighted a significant difference in the presence of EIVA both during exercise testing and at the recovery phase in $\mathrm{ChD}$ patients, with a higher frequency of ventricular arrhythmias than in healthy individuals.

\section{Autonomic balance in Chagas disease patients}

Abnormalities in autonomic function in $\mathrm{ChD}$ patients have previously been studied and associated with the destruction of parasympathetic ganglions in the heart, resulting from progressive inflammation ${ }^{(29)}$. Autonomic balance assessment using the Valsalva maneuver has been widely used in chagasic patients ${ }^{(21)(30)(31)}$ and showed no difference between the groups examined in the present study. Similarly, a recent meta-analysis ${ }^{(32)}$ demonstrated that only one of the seven studies analyzed found a significant difference in the Valsalva ratio between healthy individuals and chagasic patients without cardiopathy. The authors also reported that in certain studies that did not detect any significant difference, other autonomic indexes (such as respiratory sinus arrhythmia) were able to recognize reduced heart vagal modulation in $\mathrm{ChD}$ patients without cardiopathy.

For respiratory sinus arrhythmia, our results showed a significant difference between the groups, indicating that vagal dysfunction may occur in the absence of overt heart disease and before the development of left ventricular dysfunction ${ }^{(8)}$. Thus, left ventricular impairment might not necessarily be the cause of vagal dysfunction ${ }^{(33)}$. Indeed, the reduced respiratory sinus arrhythmia index found in $\mathrm{ChD}$ patients with or without left ventricular dysfunction may indicate a loss of synchronization between the HR and respiratory cycles, which may be related to impaired vagal modulation of the heart ${ }^{(34)}$.

Previous studies ${ }^{(22)(34)}$ have also shown reduced respiratory sinus arrhythmia indexes in $\mathrm{ChD}$ patients compared with healthy individuals (p-value $<0.001$ and $p$-value $=0.011$, respectively), and there were no differences between groups with normal $(>50 \%)$ and reduced $(\leq 50 \%) \mathrm{LVEFs}^{(34)}$. In contrast, in the present study, the main finding was the coexistence of vagal dysfunction and EIVA in ChD patients without apparent cardiac involvement. The presence of these early cardiac abnormalities suggests that there is not a clear-cut point that precisely separates individuals without apparent cardiac involvement/indeterminate disease from those with cardiac forms of $\mathrm{ChD}^{(21)}$.

The respiratory sinus arrhythmia index is inversely associated with cardiovascular disease and seems to be a strong predictor of sudden cardiac death in cardiac patients (HR 7.4; 95\% CI: 3.6-15.1; p-value $=0.0001)$. However, the prognostic significance of a reduced respiratory sinus arrhythmia index in chagasic patients without cardiac involvement needs to be further evaluated in longitudinal multicenter studies with a higher number of patients.
The increased occurrence of EIVA and vagal dysfunction in ChD patients with no apparent cardiac involvement compared with healthy individuals suggests the presence of subclinical changes, even in patients considered to be asymptomatic.

\section{CONFLICT OF INTEREST}

The authors declare that there is no conflict of interest.

\section{REFERENCES}

1. World Health Organization (WHO). Control of Chagas disease: Second report of the WHO Expert Committee. World Health Organization 2002; 95:i109.

2. Nunes MC, Carmo AA, Rocha MOC, Ribeiro AL. Mortality prediction in Chagas heart disease. Expert Rev Cardiovasc Ther 2012; 10:1173-1184.

3. Ribeiro AL, Nunes MP, Teixeira MM, Rocha MOC. Diagnosis and management of Chagas disease and cardiomyopathy. Nat Rev Cardiol 2012; 9:576-589.

4. Ribeiro AL, Rocha MOC. Indeterminate form of Chagas disease: considerations about diagnosis and prognosis. Rev Soc Bras Med Trop 1998; 31:301-314.

5. Participantes da I Reunião de Pesquisa Aplicada em Doença de Chagas. Comunicação. Validade do conceito de forma indeterminada de doença de Chagas, Araxá, MG. Rev Soc Bras Med Trop 1985; 18:46.

6. Ribeiro ALP. Disfunção autonômica e arritmia ventricular em chagásicos sem cardiopatia aparente. Rev Soc Bras Med Trop 1997; 30:257-258.

7. Nunes MC, Dones W, Morillo CA, Encina JJ, Ribeiro AL. Chagas disease: an overview of clinical and epidemiological aspects. J Am Coll Cardiol 2013; 62:767-776.

8. Ribeiro AL, Moraes RS, Ribeiro JP, Ferlin EL, Torres RM, Oliveira E, et al. Parasympathetic dysautonomia precedes left ventricular systolic dysfunction in Chagas disease. Am Heart J 2001; 141:260-265.

9. Rossi MA, Bestetti RB. The challenge of chagasic cardiomyopathy. The pathologic roles of autonomic abnormalities, autoimmune mechanisms and microvascular changes, and therapeutic implications. Cardiology 1995; 86:1-7.

10. Arena R, Myers J, Williams MA, Gulati M, Kligfield P, Balady GJ, et al. Assessment of functional capacity in clinical and research settings: a scientific statement from the American Heart Association Committee on Exercise, Rehabilitation, and Prevention of the Council on Clinical Cardiology and the Council on Cardiovascular Nursing. Circulation 2007; 116:329-343.

11. Beckerman J, Froelicher VF. Exercise-test-induced arrhythmias: a focused review. ACC Curr J Rev 2005; 14:41-44.

12. Fletcher GF, Balady GJ, Amsterdam EA, Chaitman B, Eckel R, Fleg J, et al. Exercise standards for testing and training: a statement for healthcare professionals from the American Heart Association. Circulation 2001; 104:1694-1740.

13. Morshedi-Meibodi A, Evans JC, Levy D, Larson MG, Vasan RS Clinical correlates and prognostic significance of exercise-induced ventricular premature beats in the community: the Framingham Heart Study. Circulation 2004; 109:2417-2422.

14. Elhendy A, Chandrasekaran K, Gersh BJ, Mahoney D, Burger KN, Pellikka PA. Functional and prognostic significance of exerciseinduced ventricular arrhythmias in patients with suspected coronary artery disease. Am J Cardiol 2002; 90:95-100. 
15. Jouven X, Ducimetiere P. Exercise testing: do frequent premature ventricular depolarizations represent a new criterion of positivity? Eur Heart J 2001; 22:1759-1761.

16. Lang RM, Bierig M, Devereux RB, Flachskampf FA, Foster E, Pellikka PA, et al. Recommendations for chamber quantification: a report from the American Society of Echocardiography's Guidelines and Standards Committee and the Chamber Quantification Writing Group, developed in conjunction with the European Association of Echocardiography, a branch of the European Society of Cardiology. J Am Soc Echocardiogr 2005; 18:1440-1463.

17. Nagueh SF, Appleton CP, Gillebert TC, Marino PN, Oh JK, Smiseth $\mathrm{OA}$, et al. Recommendations for the evaluation of left ventricular diastolic function by echocardiography. Eur J Echocardiogr 2009; 10:165-193.

18. Azarbal B, Hayes SW, Lewin HC, Hachamovitch R, Cohen I, Berman DS. The incremental prognostic value of percentage of heart rate reserve achieved over myocardial perfusion singlephoton emission computed tomography in the prediction of cardiac death and all-cause mortality: superiority over $85 \%$ of maximal age-predicted heart rate. J Am Coll Cardiol 2004; 44:423-430.

19. Cole CR, Blackstone EH, Pashkow FJ, Snader CE, Lauer MS. Heart-rate recovery immediately after exercise as a predictor of mortality. N Engl J Med 1999; 341:1351-1357.

20. Frolkis JP, Pothier CE, Blackstone EH, Lauer MS. Frequent ventricular ectopy after exercise as a predictor of death. N Engl J Med 2003; 348:781-790.

21. Oliveira E, Ribeiro AL, Assis Silva F, Torres RM, Rocha MOC. The Valsalva maneuver in Chagas disease patients without cardiopathy. Int J Cardiol 2002; 82:49-54.

22. Ribeiro AL, Ferreira LM, Oliveira E, Cruzeiro PC, Torres RM, Rocha MOC. Active orthostatic stress and respiratory sinus arrhythmia in patients with Chagas' disease with preserved left ventricular global systolic function. Arq Bras Cardiol 2004; 83:40-44.

23. Pereira MH, Brito FS, Ambrose JA, Pereira CB, Levi GC, Neto VA, et al. Exercise testing in the latent phase of Chagas' disease. Clin Cardiol 1984; 7:261-265.
24. Pedrosa RC, Salles JH, Magnanini MM, Bezerra DC, Bloch KV. Prognostic value of exercise-induced ventricular arrhythmia in Chagas' heart disease. Pacing Clin Electrophysiol 2011; 34:1492-1497.

25. Beckerman J, Mathur A, Stahr S, Myers J, Chun S, Froelicher V. Exercise-induced ventricular arrhythmias and cardiovascular death. Ann Noninvasive Electrocardiol 2005; 10:47-52.

26. Prakash M, Myers J, Froelicher VF, Marcus R, Do D, Kalisetti D, et al. Clinical and exercise test predictors of all-cause mortality: results from $>6,000$ consecutive referred male patients. Chest 2001; 120:1003-1013.

27. de Paola AA, Gomes JA, Terzian AB, Miyamoto MH, Martinez Fo EE. Ventricular tachycardia during exercise testing as a predictor of sudden death in patients with chronic chagasic cardiomyopathy and ventricular arrhythmias. Br Heart J 1995; 74:293-295.

28. Alencar MC, Rocha MOC, Lima MM, Costa HS, Sousa GR, Carneiro RC, et al. Heart rate recovery in asymptomatic patients with chagas disease. PLoS One 2014; 9:e100753.

29. Junqueira Junior LF, Beraldo PS, Chapadeiro E, Jesus PC. Cardiac autonomic dysfunction and neuroganglionitis in a rat model of chronic Chagas' disease. Cardiovasc Res 1992; 26:324-329.

30. Odreman RO, Davila DF, Donis JH, Torres A, Ferrer J, Inglessis I. Valsalva maneuver in chagasic patients with documented past medical history of acute chagasic myocarditis. Int J Cardiol 2004; 93:163-167.

31. Villar JC, Leon H, Morillo CA. Cardiovascular autonomic function testing in asymptomatic T. cruzi carriers: a sensitive method to identify subclinical Chagas' disease. Int J Cardiol 2004; 93:189-195.

32. Ribeiro AL, Campos MS, Baptista LM, Sousa MR. The Valsalva maneuver in Chagas disease patients without cardiopathy. Clin Auton Res 2010; 20:79-83.

33. Raadschilders L, Rocha MOC, Sousa L, Nouwen J, Ribeiro AL. Is autonomic function associated with left ventricular systolic function in Chagas heart disease patients undergoing treatment for heart failure? Rev Soc Bras Med Trop 2014; 47:239-242.

34. Neves VR, Peltola M, Huikuri H, Rocha MOC, Ribeiro AL. Respiratory sinus arrhythmia in Chagas disease. Auton Neurosci 2014; 185:149-151. 